\title{
An Effective Strategy for Human Resource Management Crisis in Enterprises
}

\author{
Chunlin Yuan \\ College of Business Administration, Zhengzhou Institute of Science and Technology Zhengzhou, \\ 450064 Zhengzhou, Henan Province P.R., China \\ yangfan5810@126.com
}

Keywords: Human resources; The crisis; Strategy

\begin{abstract}
Talent is the core competitiveness of the organization. Organization's competition is the talent competition, however, the problem of brain drain is increasingly troubled by the management of the organization, how to reduce the brain drain has become an important subject in human resource management. Brain drain is a crisis for the organization, and the management of the loss of talents should also be a kind of crisis management. In this paper,the contents and characteristics of the human resources crisis are expounded, and put forward the countermeasures to solve the crisis of human resources.
\end{abstract}

\section{Introduction}

At present, Chinese enterprises are experiencing unprecedented brain drain crisis, Which means the loss of human resource cost, and even the loss of core technology and secret leakage, business partners, talent to replace empty, which may cause internal organizational confusion disorder and organization staff morale contusion, and then lead to a sharp drop in market share, which undoubtedly bring great negative influence to the development of the organization. More serious is that the loss of the organization's top executives or other core staff has changed the strength contrast between the organization and the competitors, If there is an exodus of staff, it is likely to be a fatal blow to the organization[1,2]. Talent loss directly give rise to the talent crisis in the organization, If you do not pay attention, it will have a chain reaction, leading to the organization's credibility crisis, the crisis of information, financial crisis and business crisis. How to prevent the loss of talents, How to prevent the loss of talents, how to establish a reasonable and effective crisis management mechanism has become a problem that many domestic institutions must face.

\section{Connotation and characteristics of human resource crisis}

\subsection{The connotation of human resource crisis}

The so-called crisis, is refers to a threat to the organization's basic objectives and requires the organization make key decisions and emergency response to sudden events in a very short period of time, generally,the crisis has the characteristics of sudden, urgent and hazardouss. For enterprises, that human resources loss make the organization function suffer a great impact and even forced to interrupt, If the core staff collective resignation, the enterprise is likely to face a crowning calamity, because of this, the loss of human resources is considered enterprise crisis. In the face of the loss of human resources, enterprises should take precautions beforehand, advance the development of crisis coping strategies[3,4].

Human resources crisis management refers to the preaction before the potential or realistic crisis elements in human resource security management produce destructive effects, nip in the bud, it brings the loss to a minimum, or even benefit from it. Human resource crisis management requires the enterprise to forecast and discover the development of the external labor market and the influence of the enterprise internal management system to the staff stability, develop and implement human resource management measures to eliminate adverse effects, so as to ensure the stability of the enterprise personnel 


\subsection{Characteristics of human resource crisis}

Human resource crisis has suddenly. People tend to ignore the signs of a crisis. When the crisis occurs, the original development pattern of the enterprise suddenly upset, make people feel very suddenly.

Human resource crisis is highly uncertain. The crisis has a lot of uncertainty, it is difficult to accurately determine the time and the damage of the crisis. If there is no system of organization and human resources early warning guard well, once the crisis is coming, it is helpless.

Human resource crisis has some damage. For the human resource crisis, If the enterprise can not be properly disposed of, it leads to the enterprise image and the public lost favor to the enterprise, or even cause the bankruptcy of the enterprise.

Enterprise human resource crisis has "chain reaction". The so-called crisis "chain reaction" is a series of negative effects on the internal and external of the enterprise.

Complexity of human resource crisis. The occurrence of the human resource crisis is not determined by the single factor. For example, the external environment of the enterprise, such as the political and economic factors, corporate internal cultural atmosphere, management system, pay system, performance appraisal system, etc..

The dualnature of human resource crisis. Crisis itself is also hiding a turn for the better. First of all, it can make the enterprise realize their own shortcomings, which is conducive to the further development of enterprises. Secondly, it often causes public concern, the enterprise will win public confidence if the crisis is handled properly. Therefore, it is necessary to correctly deal with the crisis.

\section{Coping strategies of human resource management crisis}

\subsection{Establish the crisis consciousness of the brain drain}

Only by establishing the crisis consciousness of the loss of talent, can we have the sense of urgency, preventive measures and ensure the sustainable development of the organization. The organization shall fully recognize the crisis, put the crisis in heart, correctly formulate strategy and tactics of the crisis management, strengthen communication between the organization and personnel, understand the abnormal behavior of the talents in time, find the flow intention of talent as soon as possible and take reasonable measures for improvement.

Whenever and whatever, high quality talent is always scarce and irreplaceable, and always is the object of competition for all organizations.For an organization, in a sense,the ability to retain talent determines the success or failure of its operation, which the organization managers must recognize from a strategic perspective. The consciousness of the talent crisis of the organization manager is to carry out the people-oriented management in the daily work ". The recognition of talent is not only the most important resource, but also the source of the organization's core competitiveness and service objects of organizational management.

\subsection{Strengthen management, standardize operations}

The terrible thing is the loss of technology and customer resource rather than talent loss. If the managers in the organization standardize the system of job responsibilities, work flow, work report and so on, strengthen technical information and customer information management and backup, you can reduce the loss of talent to a minimum extent. Moreover, it is because of the organization's rules and regulations are not sound and management confusion that result in brain drain, which make the enterprise staff think the organization has no futuret, they think they can not achieve their aspirations, people who have these ideas are often capable. Therefore, in the long run, strengthen the organization's management system, work flow, job responsibilities, incentives and other construction, is the fundamental way to solve the loss of talent.

In summary, to retain employees of ability, to control brain drain, the key is that the organization has the strength, to have the development future, to realize the standardization management, but the organization management level, especially the human resources management each link of the 
organization directly reflects the organization is able to effectively manage the brain drain, and to minimize the negative impact of the brain drain.

\subsection{Establish a scientific, reasonable and competitive salary system}

The difference of the level of wages is one of the important reasons for the loss of talents, according to the survey, low wages is the primary factor in the cause of brain drain, account for about $68 \%$. The scientific and reasonable salary system is based on the different positions, different contributions to the organization, and evaluate the value of the job, establish a complete set of position values in the organization. And according to the position value sequence, carry out the basic salary design.

First, to achieve the internal fairness of the organization's compensation system. The organization should establish the perfect performance appraisal management system, the staff's salary and performance appraisal result link, makes the staff's income and the contribution link, realize the fairness of the organization's compensation system. This will avoid the loss of employees because of the internal distribution of injustice. In the traditional multi-wage levels of the organization, the main reason for the loss of talents lies in the question of the fairness of the organization.

Second, improve the external competitiveness of the organization's compensation system. For each job, the society has an average salary, which is the lower limit of the work of the talents. If the organization's pay is generally higher than this level, it will increase the organization's operating costs, and vice versa, it will cause a lot of talent loss. The organization may, through its own or entrust professional institutions to investigate the level of compensation in the market, determine the organization's salary level, so that the organization's compensation system in the market have a certain competitiveness, and the staff will not easily be attracted by the external organization's compensation system.

\subsection{Career planning and career development opportunities for employees}

Many organizations do not realize the importance of employee career planning. In fact, career planning play a positive role to retain staff and prevent the loss of talent. Career planning refers to the process of organizing and planning for the staff to make plans for the future career development and to help the staff to realize the plan. According to statistics, employee loyalty for the organization that provides employees with career planning is 2.2 times higher than that of an organization that does not provide a career planning. Staff will have a sense of organizational identity because of the organization providing professional career planning help, they will follow a clear, clear career path to work hard, under the help of the organization, they realize their own ultimate ideals. In this way, the possibility of brain drain will be greatly reduced[5,6].

When the organization help staff for career development planning, besides the individual work performance, manager of the organization should also consider the staff's skills and professional ethics level, planning staff's career development.Different age groups of employees with different career development strategies, development and career planning and training program. It is through the organization to design a good personal development plan and career development ladder, to attract employees, thereby reducing the flow rate and the flow tendency of employees.

\subsection{Strengthen communication, implement the shared vision of the organization, and promote the staff to identify the organization development goals.}

The most important and effective management means is to achieve the goal of the organization and to achieve the ultimate goal of the organization. Only the coordinated development of the individual goals and the organization's goals can make the employees work at ease, and reduce the loss of talents.

In the organization of internal implementation of the common vision, so that employees can have a clear understanding of the organization's development goals, the implementation of strategy, help to enhance the staff's recognition of the organization's development goals, so that all staff to form a consensus, solidarity and cooperation, and work together to achieve the organization's vision. This will avoid the loss of some of the staff, because they can not see the goal and direction of the development of the organization, do not understand the policy and strategy of the organization.Of course, the organization should also avoid the development of a common vision of the short-term, 
utilitarian and market positioning error, so that employees lose confidence in the organization and the loss.

\subsection{Create a good organizational culture and working environment}

Excellent organizational culture has a great cohesion and appeal, it can play a role in preventing the loss of talent, the role of outstanding talents aggregation. A good organizational culture will make the staff a great sense of cohesion and belonging. Organizational culture is a written or unwritten code of conduct, business philosophy, basic beliefs, values, moral values, and ways of thinking through the organization of all employees in their daily work. Through the organization's internal guidance and establishment of solidarity, hard work, efficient and orderly, full authorization, democratic equality of organization culture, and create a relaxed, comfortable working environment for employees, so that employees feel happy in the organization of work. At the same time, the management of the organization can continue to communicate with the staff on the work and life of the various problems, and can be serious and timely manner to listen to the advice and comments. Therefore, a good environment for employees is an incentive factor. Specifically, the organizational environment including system environment, work environment, interpersonal environment and psychological environment, etc.. The organization's management and the human resources department should often care about the employees work, learning, life, to help the employees to solve problems, so that employees work in a relaxed, harmonious, to the environment. Such a working environment will allow employees to be very cherish and not easily resign[7,8].

\subsection{Job rotation, advocate internal flow system}

Job rotation can not only make more and more talents to get exercise, but also easy to everyone find their most suitable jobs, so that employees become generalist. The internal flow system not only can make the staff to find their own position, but also allows the human resources department to find out the problem of frequent "outflow" sector, to take measures to remedy. In this way, the enthusiasm of all levels within the organization is fully mobilized. Break the post "a selected lifelong system", will enable staff because of the scope and the organization more loyalty, this is the job rotation to bring the huge role. Actually, to resolve the crisis in the loss of talent, the most effective way is to curb the talent produced loss of desire or is in the loss of desire in the bud when the elimination.

\subsection{Establish the mechanism of the talent flow}

The loss of the core staff may bring huge losses to the organization. In this case, the organization should use economic and legal means to restrict an employee's behavior, safeguard the legitimate rights and interests of the organization of each interest principal part, make laws of talent flow and reduce personnel for the organization to bring the negative effect of the loss. There is no perfect legislation to establish a fair competition mechanism, talent legislation is to make the exchange relationship and market operation of the talent flow legal system, set up a set of laws and regulations, the law to restrict the flow of personnel and protection, so that the flow of qualified personnel is mandatory constraints and suppression. As the core staff signed a contract, in the labor contract, the employee has a conservative organization of business secrets, technical secrets obligations, while the majority of countries to take the industry to limit the contract, which requires employees to leave the organization for a period of time, not to engage in a competitive relationship with the group work, so as to prevent the loss of confidentiality and competition.

\subsection{Establish the talent information database, improve the organization and security system}

After the crisis of the brain drain, the organization should immediately start the talent pool, quickly identify suitable candidates to replace the loss of personnel, so as to ensure the normal work of the organization system. The organization talent reserve is composed of two parts, one is the organization in daily management, pay attention to the development and training of reserve forces, such as the horizontal flow of staff, etc.; two is to maintain contact with the search company, when necessary, can be obtained from the high quality of personnel. Talent reserve must be established on the basis of the analysis of the job, according to the level of the skills required for each job and the strength to set the level of substitution. For those skills are not high or high substitution positions, can establish the external labor market reserves, in need of the organization can at any time to 
recruit; for skills required higher or alternative weak position, then focus on strengthening the organization of internal service staff training and reserves.

\subsection{The establishment of talent crisis warning management system}

The talent crisis warning system is a management activity which is to identify, analyze, judge, and make a warning and control. It is a subsystem of the system. The key is to establish the corresponding early warning indicators, such as job satisfaction, job stress, employee's sense of identity, and so on. After the establishment of early warning system, the implementation of the daily monitoring of these indicators, once they occur, the system immediately issued an early warning signal, then the organization immediately launched an analysis to clarify the causes and assess the impact of the problem, and then make the appropriate management decisions, is to improve the organization management to resolve the crisis or the official launch of the crisis management procedures. The purpose of the crisis warning management system is to find out the problems of the organization's daily personnel safety, so as to gain the time and initiative to improve the management function of the organization or to carry out the crisis management.

\section{Conclusions}

To sum up, (1) The talent is the first resource, the talent is the source of the core competitiveness of the organization, the talent is the key to the success of the future market competition. (2)It is the talent crisis consciousness and the crisis management of the talent loss that the organization is in an invincible position in the fierce market competition. (3) The organization adopts the positive measures to retain talent and attract talented people. (4) Reduce the rate of brain drain, and minimize the negative impact of the brain drain.

\section{Acknowledgements}

This work was financially supported by the key research project of university of Henan Province (15B430012).

\section{References}

[1] Jeffrey B. Arthur: The Academy of Management Journal, Vol. 37, No. 3 (Jun., 1994), pp. 670-687

[2] Patrick M. Wright, Gary C. McMahan: Human Resource Management Journal, Vol 21, no 2, 2011, pages 93-104.

[3] Rebecca R. Kehoe, Patrick M. Wright: Journal of Management Vol. 39 No. 2, February 2013 366-391.

[4] Brian Becker and Barry Gerhart:The Impact of Human Resource Management on Organizational Performance: Progress and Prospects.The Academy of Management Journal, Vol. 39, No. 4 (Aug., 1996), pp. 779-801

[5] Nina Gupta, Jason D. Employee compensation: The neglected area of HRM research. Human Resource Management Review 24 (2014) 1-4

[6] Nicholas Aston Beadles II, Christopher M. Lowery, Kim Johns:The Impact of Human Resource Information Systems: An Exploratory Study in the Public Sector. An Exploratory Study in the Public Sector," Communications of the IIMA: V ol. 5: Iss. 4, Article 6

[7] MalcolmWarner: Challenges of human resource management in Japan. http://dx.doi.org/10.1080/13602381.2012.659958

[8] Valerie Anderson, Thomas Garavan, Eugene Sadler-Smith: Human Resource Development International. Valerie Anderson, Thomas Garavan \& Eugene Sadler-Smith (2014) Corporate social responsibility, sustainability, ethics and international human resource development, HumanResource Development International, 17:5, 497-498, DOI: 10.1080/13678868.2014.954187 